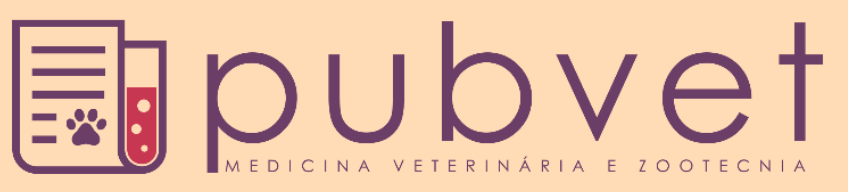

https://doi.org/10.31533/pubvet.v15n02a750.1-6

\title{
Infecção urinária por Citrobacter koseri ( $C$. diversus) em cão portador de nefrolitíase
}

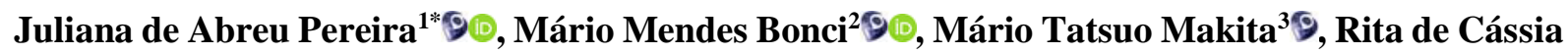 \\ Campbell Machado Botteon ${ }^{4} \Phi$, Miliane Moreira Soares de Souza ${ }^{5} \oplus \odot$, Ana Carolina de Oliveira \\ Almeida $^{69}$, Anielli da Costa Pinheiro ${ }^{7}$, Talita Wajczyk ${ }^{80}$, Katherinne Barth Wanis Figueiredo ${ }^{80}$ \\ ${ }^{1}$ Docente do curso de Medicina Veterinária da Universidade Sociedade Educacional de Santa Catarina (UNISOCIESC), Joinville - SC, Brasil. \\ ${ }^{2}$ Doutorando em Diagnóstico Bucal, Radiologia Odontológica e Imaginologia pela Universidade de São Paulo (USP). São Paulo - SP, Brasil \\ ${ }^{3}$ Mestre pelo Programa de Pós-Graduação em Medicina Veterinária da Universidade Federal Rural do Rio de Janeiro (UFRRJ). \\ ${ }^{4}$ Docente, Departamento de Medicina e Cirurgia Veterinária, Instituto de Veterinária - UFRRJ, Seropédica, RJ \\ ${ }^{5}$ Docente, Departamento de Microbiologia e Imunologia Veterinária, Instituto de Veterinária - UFRRJ, Seropédica, RJ \\ ${ }^{6}$ Médica Veterinária, graduada pela UFRRJ \\ ${ }^{7}$ Médica Veterinária, pós-graduada pelo Curso de Especialização em Nefrologia e Urologia de pequenos animais da Associação Nacional de \\ Clínico Veterinários de Pequenos Animais (Anclivepa) São Paulo - SP \\ ${ }^{8}$ Discente do curso de Medicina Veterinária da UNISOCIESC, campus Joinville. Joinville - SC Brasil \\ *Autor para correspondência, E-mail: juliana.abreu@unisociesc.com.br
}

Resumo: Litíases são definidas como concreções formadas através da deposição de minerais ao redor de um núcleo formado por matriz orgânica. Podem se localizar em qualquer região do trato urinário dos animais, causando obstruções ou infecção do trato urinário (ITU). Apenas 10\% dos urólitos podem ser encontrados nos rins, sendo esta localização pouco frequente. Citrobacter koseri possui raro isolamento nas ITUs em cães. O presente relato teve por objetivo descrever o diagnóstico clínico, bem como o diagnóstico microbiológico e tratamento da infecção por este microrganismo em um animal adulto portador de nefrolitíase bilateral. A paciente em questão vinha sendo tratada para doença renal crônica (DRC) há dois meses com pouca melhora do quadro de azotemia. Através de exames laboratoriais e de imagem houve diagnóstico de infecção urinária associada à nefrolitíase bilateral. Após manejo clínico da ITU, houve cura microbiológica da paciente e discreta redução do tamanho das litíases. O controle da DRC foi realizado até o óbito. As avaliações diagnósticas reiteram a importância do diagnóstico precoce de litíases e ITU a fim de prevenir lesões irreversíveis nos rins e vias urinárias. Citrobacter koseri deve ser incluído como um patógeno de importância nas infecções urinárias em cães, uma vez que urolitíases favorecem a contaminação do trato urinário, com possibilidade de desenvolvimento de DRC.

Palavras-chave: Urolitíase, urocultura, manejo clínico

\section{Urinary infection by Citrobacter koseri (C. diversus) in a dog affected by nephrolithiasis}

Abstract. Lithiasis is defined as concretions formed by mineral deposition around a core
formed by the organic matrix. They can be located in any region of animals' urinary tract,
causing obstruction or urinary tract infection (UTI). Only ten percent of uroliths can be
found in the kidneys, being this an uncommon location. Citrobacter koseri, a
microorganism of important isolation in human's bacteremias, is rarely isolated in dogs.
The present report aimed to describe the clinical diagnosis, as a microbiological diagnosis
of the infections caused by this microorganism of infrequent occurrence, in an adult animal
carrying bilateral nephrolithiasis. The patient described was being treated for chronic
kidney disease (CKD) for two months without any improvement of the azotemia state. 
Through laboratory and image tests there was a diagnosis of urinary tract infection associated with bilateral nephrolithiasis. After UTI's clinical management there was a patient's microbiological cure and slight reduction of lithiasis size. The CKD's control was done due to an animal's death. The diagnostic evaluations confirm the importance of earlier diagnosis of UTI and lithiasis to prevent irreversible damage to the kidneys and urinary pathways. Citrobacter koseri should be included as an important pathogen in dog's urinary infections once the urinary tract is the main isolation site and urolithiasis favor the urinary tract's contamination with possibilities of developing CKD.

Keywords: Urolithiasis, uroculture, clinical management

\section{Infección del tracto urinario por Citrobacter koseri (C. diversus) en un perro con nefrolitiasis}

Resumen. La litiasis se define como concreciones formadas a través de la deposición de minerales alrededor de un núcleo formado por una matriz orgánica. Se pueden ubicar en cualquier región del tracto urinario de los animales, causando obstrucciones o infección del tracto urinario (ITU). Solo el 10\% de los urolitos se pueden encontrar en los riñones, y esta ubicación es poco común. Citrobacter koseri tiene un aislamiento raro en las infecciones urinarias en perros. El presente informe tuvo como objetivo describir el diagnóstico clínico, así como el diagnóstico microbiológico y el tratamiento de la infección por este microorganismo en un animal adulto con nefrolitiasis bilateral. El paciente en cuestión había sido tratado por enfermedad renal crónica (ERC) durante dos meses con poca mejoría en la azotemia. A través de exámenes de laboratorio y de imágenes, se diagnosticó un diagnóstico de infección urinaria asociada con nefrolitiasis bilateral. Después del tratamiento clínico de la infección urinaria, hubo una cura microbiológica del paciente y una ligera reducción en el tamaño de la litiasis. El control de la ERC se realizó hasta la muerte. Las evaluaciones de diagnóstico reiteran la importancia del diagnóstico precoz de litiasis e ITU para evitar daños irreversibles en los riñones y el tracto urinario. Citrobacter koseri debe incluirse como un patógeno de importancia en las infecciones urinarias en perros, ya que la urolitiasis favorece la contaminación del tracto urinario, con la posibilidad de desarrollar ERC.

Palabras clave: Urolitiasis, urocultivo, manejo clínico

\section{Introdução}

Urolitíase pode ser definida como a presença de concreções em qualquer dos órgãos componentes do sistema urinário, com localizações diversas, acometendo desde a pelve renal até a uretra (Calabrò et al., 2011; Osborne et al., 2009). Predisposição familiar ou racial, defeitos congênitos, lesões adquiridas e alimentação inadequada são fatores predisponentes à formação de litíases no trato urinário (TU) (Hunprasit et al., 2017; Mack \& Kienzle, 2017). Fármacos como corticosteróides, antibióticos, quimioterápicos e modificadores do $\mathrm{pH}$ urinário também favorecem a produção de concreções no TU (Osborne et al., 2009). Noventa por cento das litíases são encontradas no trato urinário inferior (TUI), sendo os nefrólitos considerados menos frequentes (10\%) (Dibartola \& Westropp, 2015).

Infecções do trato urinário (ITUs) costumam ter correlação com a ocorrência de urolitíases. Del Angel-Caraza et al.(2010) e Palma et al. (2013) relataram que ITUs frequentemente são causadas por bactérias urease positivas, tais como Staphylococcus intermedius e Proteus sp.; e que os urólitos são secundários ao processo infeccioso, sendo a estruvita o tipo de cálculo mais comumente formado. Outra hipótese defendida por estes autores é que a infecção ocorre secundariamente à retenção urinária em pacientes portadores de litíases, o que fornece um meio propício ao crescimento microbiano no trato urinário.

Citrobacter koseri, anteriormente denominado C. diversus, é um microrganismo Gram-negativo que possui raro isolamento, porém constitui importante causador de bacteremias em humanos. É relatada ocorrência de abscessos cerebrais e meningite (Liu et al., 2015), sendo descrita ocorrência semelhante e 
septicemia em um bezerro (Komine et al., 2014). Drelichman \& Band (1985) conduziram um estudo com 31 adultos portadores de bacteremia por $C$. diversus; desses, $65 \%$ dos pacientes eram idosos e $77 \%$ adquiriram a bactéria em ambiente hospitalar. $O$ trato urinário foi o principal sítio de infecção, seguido do trato gastrointestinal (TGI) e feridas. Ainda neste mesmo estudo, $48 \%$ dos pacientes portadores de bacteremia por Citrobacter vieram à óbito.

O presente trabalho teve por objetivo relatar o diagnóstico clínico, microbiológico e tratamento de ITU por Citrobacter koseri, em um cão adulto portador de nefrolitíase bilateral.

\section{Relato de caso}

Um canino, fêmea, da raça Poodle, com 5 anos de idade, não castrada e com peso corporal de $4,8 \mathrm{~kg}$ foi atendido no Setor de Pequenos Animais do Hospital Veterinário da Universidade Federal Rural do Rio de Janeiro (HVPA-UFRRJ). Durante a anamnese realizada no primeiro dia de atendimento foi relatado que a cadela apresentava azotemia persistente diagnosticada por avaliações de ureia e creatinina séricas realizadas dois meses antes desta avaliação. Exames bioquímicos realizados sete dias antes do atendimento demonstraram valores de ureia $(242 \mathrm{mg} / \mathrm{dL})$ e creatinina $(4,9 \mathrm{mg} / \mathrm{dL})$ elevados, caracterizando quadro de nefropatia crônica. A paciente foi submetida anteriormente à terapia através de fluidoterapia com $150 \mathrm{~mL}$ de solução fisiológica $0,9 \%(\mathrm{NaCl} 0,9 \%)$ por via subcutânea a cada 48 horas, apresentando pouco resultado de melhora dos parâmetros laboratoriais. A alimentação do animal era baseada principalmente em ração comercial premium para filhotes sendo esta dieta substituída ao início dos quadros de azotemia por ração específica para cães nefropatas.

Ao exame clínico, a paciente apresentava-se com todos os parâmetros dentro da normalidade. Não foram relatados sinais clínicos relacionados ao TGI. Foi descrita a ocorrência de poliúria, com urina de coloração amarela. Nesta data foram solicitados os seguintes exames: hemograma completo, bioquímica sérica, urinálise, cultura com antibiograma da urina e ultrassonografia (USG) abdominal para melhor determinação da condição clínica do animal. Os resultados dos exames laboratoriais solicitados nesta avaliação, bem como os parâmetros de referência para hematologia (Weiss \& Wardrop, 2010), bioquímica sérica (Kahn, 2010) e urinálise (Feldman \& Sink, 2008) estão demonstrados na Tabela 1.

Tabela 1. Avaliações laboratoriais (hemograma, bioquímica e urinálise) realizadas no dia 0 (D0) de atendimento clínico.

\begin{tabular}{lcc}
\hline Parâmetro & Resultado & Valor de referência \\
\hline Hematócrito & Hemograma & $37-55 \%$ \\
Leucometria global & 40,5 & $6.000-17.000 / \mu \mathrm{L}$ \\
Plaquetas & 14.800 & $200.000-500.000 / \mu \mathrm{L}$ \\
Proteína plasmática total & 435.000 & $6,0-7,5 / \mu \mathrm{L}$ \\
\hline & 7,6 & $15-40 \mathrm{mg} / \mathrm{dL}$ \\
\hline Ureia & Bioquímica & $0,5-1,4 \mathrm{mg} / \mathrm{dL}$ \\
Creatinina & 122 & $2,9-5,3 \mathrm{mg} / \mathrm{dL}$ \\
Fósforo & 3,5 & $1,3-1,5 \mathrm{mmol} / \mathrm{L}$ \\
Cálcio iônico & 4,9 & $2,3-3,1 \mathrm{~g} / \mathrm{dL}$ \\
Albumina & 1,24 & $142-152 \mathrm{mmol} / \mathrm{L}$ \\
Sódio & 3,2 & $3,9-5,1 \mathrm{mmol} / \mathrm{L}$ \\
Potássio & 149 & $1015-1045$ \\
\hline & 4,2 & $5,5-7,5$ \\
Densidade & Urinálise & Ausente \\
pH & 1006 & Ausente \\
Sangue & 8,0 & $0-4$ \\
Proteínas & ++ & $0-4$ \\
Hemácias/campo & ++ & Ausente \\
Leucócitos/campo & $5 /$ campo & Ausente \\
Cristais & $10 /$ campo & Ausente \\
Cilindros & Ausente & $<0,5$ \\
Bactérias & Ausente & \\
Proteína/creatinina urinária & 1,25 &
\end{tabular}


Na USG foram observadas nefrolitíases em ambos os rins, tendo comprimento de 3,0 cm para a litíase do rim esquerdo e $2,15 \mathrm{~cm}$ para a litíase do rim direito. Ambos os órgãos apresentavam contorno irregular, aumento de ecogenicidade e arquitetura preservada. No momento do exame de imagem foram colhidos $20 \mathrm{~mL}$ de urina por cistocentese para urinálise (Elementos Anormais e Sedimentos - EAS); relação proteína/creatinina urinária (UPC) e cultura com antibiograma. A urinálise revelou hipostenúria (1.006), $\mathrm{pH}$ urinário discretamente aumentado $(8,0)$, hematúria $(++)$, proteinúria $(++)$, piúria, microbiota incontável constituída por cocos e bastonetes. $\mathrm{O}$ valor da UPC correspondeu à pouco mais que o dobro do valor máximo de referência (1,25 - referência animal proteinúrico UPC > 0,5).

A amostra de urina foi acondicionada em frasco estéril e enviada imediatamente para o Laboratório de Diagnóstico Microbiológico Veterinário da UFRRJ. O isolamento de bactérias patogênicas foi realizado conforme descrito por (Koneman et al., 2012) e a avaliação do perfil de suscetibilidade antimicrobiana (CLSI, 2012; Wibowo, 2013). No cultivo de 48 horas observou-se o crescimento de Citrobacter koseri (C. diversus) e a contagem bacteriana foi maior que 30.000 unidades formadoras de colônia por mililitro (> $30.000 \mathrm{UFC} / \mathrm{mL}$ ), caracterizando assim, a infecção do trato urinário por este agente. Quanto ao perfil de suscetibilidade, a amostra foi sensível às associações de ampicilina + sulbactam e sulfametoxazol + trimetoprima; e aos antibióticos enrofloxacina, amoxicilina e norfloxacina. Entretanto, foi resistente aos fármacos nitrofurantoína e gentamicina.

Mediante avaliação de todos os exames foi sugerida a ocorrência de ITU associada à nefrolitíase, sendo estruvita a provável composição destes cálculos, de acordo com o pH urinário elevado e associação com ITU; suspeita não confirmada na avaliação do sedimento urinário, uma vez que a cristalúria não esteve presente. Foi instituído o tratamento com enrofloxacina na dose de $5 \mathrm{mg} / \mathrm{kg}$ a cada 24 horas por 20 dias; ácidos graxos ômega 3 na dose de $100 \mathrm{mg} / \mathrm{kg}$ a cada 24 horas por 30 dias; tramadol na dose de $1,25 \mathrm{mg} / \mathrm{kg}$ a cada 12 horas por 10 dias e ração terapêutica para dissolução de cristais de estruvita, na quantidade diária de 60 gramas, divididos em duas refeições. Em virtude de ocorrência de vômitos ao início da nova alimentação, retornou-se à utilização da dieta para nefropatas, sendo mantidas todas as demais medicações. A fluidoterapia por via subcutânea foi mantida, uma vez que a proprietária não dispunha de condições financeiras para internação e cuidados hospitalares.

O animal retornou para reavaliações clínicas quatro meses após a data indicada, sendo solicitados novos exames laboratoriais. Os exames realizados por outro profissional sete dias antes do atendimento revelaram valores de uréia $(168 \mathrm{mg} / \mathrm{dL})$ e creatinina $(2,0 \mathrm{mg} / \mathrm{dL})$ ainda elevados. Ao EAS observou-se: densidade 1.010; pH 6,5; proteinúria (+), sangue oculto (+++), hemácias e leucócitos aumentados (+++), células descamativas $(++)$ e de transição $(++++)$. Houve perda de peso desde o início do tratamento (peso vivo de 4,150 Kg nesta avaliação), porém melhor controle da azotemia. Apetite e ingestão hídrica da paciente foram descritos como normais e o exame físico também não evidenciou alterações. Uma nova amostra de urina colhida por cistocentese foi obtida a fim de esclarecer a evolução clínica da ITU anteriormente diagnosticada. A nova avaliação por USG revelou redução considerável da litíase do rim esquerdo $(2,36 \mathrm{~cm}$ - redução de $0,64 \mathrm{~cm})$ e discreto aumento da litíase do rim direito $(2,46 \mathrm{~cm}$ - aumento de $0,31 \mathrm{~cm}$ ). Neste momento o objetivo do tratamento foi melhorar a condição funcional renal e reduzir ao máximo o tamanho dos urólitos focando em um procedimento cirúrgico para remoção dos mesmos. Foi instituída terapia com associação de $25 \mathrm{mg}$ de condroitina $+125 \mathrm{mg}$ de glucosamina, por via oral, a cada 24 horas por 60 dias; além do uso de formulação manipulada com extrato de cramberry $(10 \mathrm{mg} / \mathrm{kg})$ e associações (unha de gato na dose de $20 \mathrm{mg} / \mathrm{kg}$ e vitamina C na dose de $10 \mathrm{mg} / \mathrm{kg}$ ), por via oral, a cada 24 horas por 30 dias para evitar infecções urinárias recorrentes. A terapia conservadora para DRC, bem como a fluidoterapia foram mantidas. Quatro dias após a coleta de amostras foi liberado o laudo microbiológico onde não houve crescimento bacteriano na amostra após 48 horas de cultivo. Após este período, foi mantido o acompanhamento clínico, laboratorial e por USG da paciente; uma vez que a proprietária não possuía condições financeiras para realização da cirurgia. $\mathrm{O}$ animal veio a óbito aproximadamente seis meses após o primeiro atendimento em decorrência de complicações oriundas de azotemia severa.

\section{Discussão}

Concreções minerais podem ocorrer em diversas regiões do TU dos animais, com distintos processos de etiopatogenia; porém nem todos os pacientes manifestam sinais clínicos consideráveis até que haja 
piora da função renal ou infecção associada à urolitíase. Olsen (2004) afirmou que sinais como hematúria, pielonefrite, DRC e dor abdominal/sublombar podem ocorrer em animais sem processos obstrutivos. Urólitos localizados em regiões passíveis de obstrução podem causar ruptura de estruturas de vias urinárias, cursando com quadro clínico de uremia grave (Bebchuck, 2004). Para o animal deste relato, durante todo o período de tratamento não ocorreu ruptura ou obstrução dos órgãos do sistema urinário dada à relação de diâmetro do urólito e o diâmetro de passagem dos órgãos envolvidos, apesar da uremia persistente.

Estudos afirmam que cálculos de estruvita e oxalato de cálcio são os tipos mais frequentes em cães, sendo fosfato triplo magnesiano o urólito mais correlacionado com ITU`s nestes animais (Bebchuck, 2004; Fromsa et al., 2011; Houston et al., 2004; Hunprasit et al., 2017; Tion et al., 2015). Dados científicos em associação com resultados de EAS (pH alcalino) e urocultura com antibiograma positiva, condições clínicas do animal e condições financeiras da proprietária contribuíram com a decisão de terapia clínica com foco na dissolução do cristal de estruvita, pressupondo-se pelos resultados dos exames, que a natureza mineral do cristal seria esta. Com esta terapêutica, resultados consideráveis de redução da litíase em rim esquerdo foram obtidos, porém houve discreto aumento na litíase do rim direito, podendo-se inferir que a litíase direita provavelmente possuía outra composição mineral; e a litíase esquerda poderia ter composição mineral mista, ou que o tempo de tratamento para dissolução deste cristal não foi suficiente. A condição clínica da paciente, bem como as condições funcionais renais e os poucos recursos financeiros da proprietária, foram os fatores limitantes à realização do procedimento cirúrgico de pielolitotomia; que seria indicado para resolução do caso clínico.

Lulich et al. (2004) afirmaram que os cálculos podem lesionar o epitélio do TU, favorecendo a ocorrência de ITU. No caso descrito, a paciente apresentava uma infecção urinária por tempo considerável que, associada ao processo irritativo causado pela presença do cálculo e demora no diagnóstico de litíase levaram ao desenvolvimento de DRC, sendo o aumento da ecogenicidade e contorno irregular dos rins evidências na alteração do órgão. Cálculos e infecções urinárias devem ser brevemente diagnosticados e tratados, uma vez que, caso o processo agressor persista, os danos à função renal tornam-se irreversíveis.

Apesar do isolamento pouco frequente, a cepa de Citrobacter koseri (C. diversus) encontrada neste caso foi sensível às associações de ampicilina + sulbactam (bactericida da classe penicilina betalactamases sendo o sulbactam o responsável por ampliar o espectro antimicrobiano) e sulfametoxazol + trimetoprima (da classe sulfonamidas, impedindo a síntese de ácido fólico); e aos antibióticos amoxicilina (classe penicilina com ação bactericida, interferindo na parede celular) e norfloxacina (da classe de quinolona com ação bactericida por inibição da síntese de DNA), mesmo sendo esses os antibióticos usados comumente e com risco de resistência microbiana. A localização da infecção foi semelhante ao descrito por Drelichman \& Band (1985), porém o desfecho clínico foi distinto do relatado para a maioria dos pacientes. Isto se deu, provavelmente, devido ao quadro de azotemia persistente, o qual leva a um desequilíbrio da homeostase do organismo provocando graves consequências, dificultando o manejo por parte do médico veterinário, aumentando assim, a chance de morte destes animais.

\section{Considerações finais}

Citrobacter koseri (C. diversus) deve ser incluído como um patógeno de importância nas infecções urinárias em cães, uma vez que o trato urinário constitui o principal sítio de isolamento deste microrganismo e urolitíases favorecem a contaminação do trato urinário, com possibilidade de desenvolvimento de DRC.

\section{Referências}

Bebchuck, T. N. (2004). Cálculos e neoplasias na bexiga. HARARI, J. Segredos Em Cirurgia de Pequenos Animais. Porto Alegre: Artmed, 231-236.

Calabrò, S., Tudisco, R., Bianchi, S., Grossi, M., Bonis, A., \& Isabella Cutrignelli, M. (2011). Management of struvite uroliths in dogs. British Journal of Nutrition, 106(S1), S191-S193. https://doi.org/10.1017/S0007114511000882 
CLSI. (2012). Methods for dilution antimicrobial susceptibility tests for bacteria that grow aerobically; approved standard 9th edition. CLSI document M07-A9. Clinical and Laboratory Standards Institute, 32, 88.

Del Angel-Caraza, J., Diez-Prieto, I., Pérez-García, C. C., \& García-Rodríguez, M. B. (2010). Composition of lower urinary tract stones in canines in Mexico City. Urological Research, 38(3), 201-204. https://doi.org/10.1007/s00240-009-0248-7

Dibartola, S. P., \& Westropp, J. L. (2015). Manifestações clínicas das doenças do trato urinário. In Nelson, R. W., Couto, C. G. Medicina Interna de Pequenos Animais. 5 ed. Rio de Janeiro: Elsevier.

Drelichman, V., \& Band, J. D. (1985). Bacteremias due to Citrobacter diversus and Citrobacter freundii. Archives of Internal Medicine, 145(10), 1808. https://doi.org/10.1001/archinte.1985.00360100068010

Feldman, B. F., \& Sink, C. A. (2008). Urinálise e Hematologia - Laboratorial para o Clínico de Pequenos Animais (Roca; $1^{\text {a }}$ edição (ed.)). ROCA. https://books.google.com.br/books?id=zoJa1wvVtNAC

Fromsa, A., Saini, N. S., \& Rai, T. S. (2011). Diagnosis, prediction and mineral analysis of uroliths in canines. Global Veterinaria, 7(4), 610-617.

Houston, D. M., Moore, A. E. P., Favrin, M. G., \& Hoff, B. (2004). Canine urolithiasis: a look at over 16000 urolith submissions to the Canadian Veterinary Urolith Centre from February 1998 to April 2003. The Canadian Veterinary Journal, 45(3), 225-230. http://www.ncbi.nlm.nih.gov/pubmed/15072194

Hunprasit, V., Osborne, C. A., Schreiner, P. J., Bender, J. B., \& Lulich, J. P. (2017). Epidemiologic evaluation of canine urolithiasis in Thailand from 2009 to 2015. Research in Veterinary Science, 115, 366-370. https://doi.org/10.1016/j.rvsc.2017.07.008

Kahn, C. M. (2010). The merck veterinary manual. Merck \& Co (M. \& C. $10^{\mathrm{a}}$ Edição (ed.)). Whitehouse Station.

Komine, M., Massa, A., Moon, L., \& Mullaney, T. (2014). Citrobacter koseri Septicaemia in a Holstein Calf. Journal of Comparative Pathology, 151(4), 309-313. https://doi.org/https://doi.org/10.1016/j.jcpa.2014.07.005

Koneman, E., Winn Jr, W., Allen, S., Janda, W., Procop, G., Schreckenberber, P., \& Woods, G. (2012). Diagnóstico microbiológico: texto e atlas colorido. In Diagnóstico microbiológico: texto e atlas colorido (pp. xxxv-1565).

Liu, H.-W., Chang, C.-J., \& Hsieh, C.-T. (2015). Brain abscess caused by Citrobacter koseri infection in an adult. Neurosciences, 20(2), 170-172. https://doi.org/10.17712/nsj.2015.2.20140749

Lulich, J. P., Osborne, C. A., Bartges, J. W., \& Lekcharoensuk, C. (2004). Distúrbios do trato urinário inferior dos caninos. Tratado de Medicina Interna Veterinária: Doenças Do Cão e Do Gato, 2, 5.

Mack, J., \& Kienzle, E. (2017). Ungewöhnlicher Fall von Struvit-Urolithiasis bei einem Hund. Tierärztliche Praxis Ausgabe K: Kleintiere / Heimtiere, 45(05), 344-351. https://doi.org/10.15654/TPK-160993

Olsen, D. (2004). Ruptura e cálculos ureterais. HARARI, J. Segredos Em Cirurgia de Pequenos Animais. Porto Alegre: Artmed, 228-230.

Osborne, C. A., Lulich, J. P., Kruger, J. M., Ulrich, L. K., \& Koehler, L. A. (2009). Analysis of 451,891 Canine Uroliths, Feline Uroliths, and Feline Urethral Plugs from 1981 to 2007: Perspectives from the Minnesota Urolith Center. Veterinary Clinics of North America: Small Animal Practice, 39(1), 183-197. https://doi.org/10.1016/j.cvsm.2008.09.011

Palma, D., Langston, C., Gisselman, K., \& McCue, J. (2013). Canine struvite urolithiasis. Compend Contin Educ Vet, 35(8), 457-458.

Tion, M., Dvorska, J., \& Saganuwan, S. (2015). A review on urolithiasis in dogs and cats. Bulgarian Journal of Veterinary Medicine, 18(1), 1-18. https://doi.org/10.15547/bjvm.806

Weiss, D. J., \& Wardrop, J. K. (2010). Schalm's Veterinary Hematology.

Wibowo, A. (2013). Performance standards for antimicrobial susceptibility testing: 23rd informational supplement M100-S23. Performance Standards for Antimicrobial Susceptibility Testing: 23rd Informational Supplement M100-S23, 33, 62-65.

Histórico do artigo:

Aprovado: 15 de outubro de 2020.

Disponível online: 18 de dezembro de 2020.
Licenciamento: Este artigo é publicado na modalidade Acesso Aberto sob a licença Creative Commons Atribuição 4.0 (CC-BY 4.0), a qual permite uso irrestrito, distribuição, reprodução em qualquer meio, desde que o autor e a fonte sejam devidamente creditados 